\title{
El pueblo en armas. Vicálvaro y el golpe de 1936
} Introducción

La Guerra Civil española es el segundo conflicto bélico sobre el que más se ha

El presente artículo tiene como objetivo recuperar lo acontecido en el pueblo de Vicálvaro entre los días 17 y 20 de julio de 1936. Con este fin, se acudió a documentación clave que ha permitido reconstruir el día a día de la vida del pueblo y, sobre todo, del cuartel de artillería ligera N. ${ }^{\circ}$ 2, que protagonizó el alzamiento en este cantón de Madrid. Del análisis de la información se desprenden conclusiones locales que pueden contribuir al debate sobre otras cuestiones, como el teórico derrumbe del Estado republicano tras la sublevación.

Palabras clave: golpe, sublevación, Vicálvaro, historia, República.

-Profesor-Investigador del Instituto Universitario de Investigación Ortega y Gasset (IUIOG).

ivancible@yahoo.es escrito, sólo después de la Segunda Guerra Mundial, de la cual, en definitiva, forma parte como primer episodio. Sin embargo, ¿sabemos todo sobre aquella guerra? ¿Qué no sabemos? ¿Por qué no lo sabemos? Todavía quedan muchas preguntas sin respuesta.

Con el argumento de "no reabrir viejas heridas" quedaron preguntas sin responder, lo que ha servido de coartada para no profundizar más en la comprensión de este pasado, al que acercarse siempre ha sido difícil pues su percepción en nuestro presente es todavía intensa. Quizás sea posible un acercamiento aséptico a aquellos tres años de la historia de España, pero... ¿es deseable? ¿Es posible acercarse a aquellos españoles que vivieron aquella tragedia sin conmoverse? ¿Inhabilita esa subjetividad para recorrer y explicar aquellos episodios? Al ser parte interesada, ¿puede el historiador darles forma con palabras y que estas sean veraces? El presente artículo pretende 
ser un acercamiento a la historia real con la mayor honestidad y vocación posibles.

Hablando de estas dos virtudes, el miedo puede ser un enemigo suyo cuyo efecto permanece durante años, lustros, incluso décadas. La dictadura ayudó a que la labor de los historiadores fuera una tarea difícil y obstaculizada. Si la guerra polarizó los sentimientos, el franquismo tejió un "nuevo traje" con el cual "vestir" la realidad a su medida. Mientras se cavaban fosas para enterrar a miles de fusilados, el miedo se encargaba de enterrar las conciencias y callar las voces disidentes, y puede reconocerse que se hizo una magnífica labor en función de esos objetivos, aunque el segundo de ellos era utópico: si bien se puede convertir en inerte la materia viva, no se pueden exterminar las creencias, y menos aún la historia. La inquietud del ser humano por saber, la necesidad de conocer qué sucedió en nuestros pueblos y con nuestros seres queridos nunca desaparece.

A lo largo de esta investigación se ha podido comprobar cómo sigue vivo el miedo que sembraron la guerra y el franquismo, entorpeciendo, y en alguna ocasión impidiendo, la labor del historiador. Pero el miedo se va diluyendo con el tiempo, y entonces da paso a las preguntas, que vuelven con fuerza empujadas por la tercera generación de los protagonistas de nuestra guerra.

Los vencedores impusieron su lectura de la historia al mismo tiempo que ejecutaban distintas acciones, formales e informales, encaminadas a silenciar la voz de los derrotados. Miles de tradiciones orales fueron "calladas" con el silencio del miedo; miles de familias pusieron el contador de su historia en ceros a partir del año 1939.

Buena parte de los objetivos fueron alcanzados, pues se logró con éxito "amputar" momentos de las historias familiares, consiguiendo que el vínculo de la tradición oral de abuelos, hijos y nietos quedara quebrado. Hemos convivido con personas cuyo sufrimiento iba oculto; seres humanos 
que tuvieron que vivir con la humillación de la derrota todos los días de su vida.

El silencio que el franquismo impuso a los españoles derrotados ha supuesto un daño irreparable a la posibilidad de conocer la verdad de los hechos. Ese silencio se ha llevado miles de historias, de entrevistas, de documentos, de informaciones que hubieran enriquecido de forma definitiva el conocimiento de aquel trágico episodio de la historia de España. Obviamente, conocemos mucho y bien de los grandes acontecimientos, grandes batallas y grandes tomas de decisiones, pero la "niebla" no se ha disipado para las innumerables historias que en el ámbito de lo local se produjeron durante los años 1936-1939, y durante el periodo de la represión posterior.

Sin embargo, todavía hay tiempo para "encender" algunas luces que permitan mirar con mayor nitidez y entender mejor esa parte de nuestra historia. Están saliendo a la luz miles de pequeñas historias gracias a la iniciativa de cientos de improvisados historiadores y de las nuevas generaciones de familiares de aquellos que fueron protagonistas de la guerra.

Como dice, desde la honestidad y la vocación, el historiador y experto en la Guerra Civil, Severiano Montero:

El procedimiento adecuado para superar este conflicto no es ignorarlo, como tantas veces se repite, sino tratar de comprenderlo. Una tarea costosa, pero necesaria si se quiere evitar su repetición (Montero, 2009, p. II).

En las siguientes páginas no se van a abordar las distintas fases por las que el conflicto fue mutando hasta su desenlace, que, por otro lado, son sobradamente conocidas. Centraremos este artículo en el que a nuestro parecer es el momento decisivo y esencial para entender el devenir de 
los sucesos, es decir, su origen, que no fue otro que el fijado en julio de 1936.

Una de las cuestiones comúnmente mencionadas es el derrumbamiento del Estado republicano después del alzamiento de los días 17 y 18 de julio. Sin embargo, el propio acontecer de lo ocurrido nos enseña que la República no desapareció el 18 de julio de 1936, sino que se mantuvo viva hasta la primavera de 1939. ¿Cómo es posible que un Estado superado por la anarquía, traicionado y enfrentado por su propio Ejército, atacado por las potencias fascistas y abandonado por las democracias "hermanas" lograra sobrevivir 3 años más?

Sabemos que los políticos republicanos, los leales, dejaron mucho que desear, salvo honradas excepciones. Sabemos que el Ejército traicionó al Estado, aunque quedaron lealtades como la del general Rojo, quien, gracias a su brillantez y a la entrega de cientos de miles de milicianos, logró alargar y exprimir el esfuerzo bélico de la República. Sabemos que hubo decenas de regimientos alzados, pero también numerosos fracasos gracias a la acción del pueblo en armas que en definitiva mantuvo viva a la República.

Si bien es prácticamente imposible reconstruir los acontecimientos de aquellos días con la exactitud y riqueza de detalles que se hubiera podido décadas atrás, es necesario reivindicar la vocación y hacer el último esfuerzo por recuperar toda la información que nos queda, siendo imprescindible seguir investigando y aportando luz a aquellos hechos que marcaron para siempre la historia de España.

\section{Metodología}

Este artículo es consecuencia de una investigación de 2 años, tiempo en el que se realizó una labor ingente de búsqueda de fuentes que ayudaran a aportar luz a los acontecimientos de julio de 1936 en Vicálvaro.

\section{4}


El trabajo en archivos ha sido clave para la elaboración del artículo, siendo el Centro Documental de la Memoria Histórica (CDMH) la principal vía de acceso a la documentación, a las fuentes primarias, gracias a su digitalización de miles de documentos, entre los que se encuentran los relativos a la "Causa General", ${ }^{1}$ llamado así oficialmente el proceso en el que quedó enmarcado el enjuiciamiento de los hechos que son nuestro objeto de estudio.

El análisis de la documentación se realizó a través de la elaboración de fichas de acuerdo a cada una de las declaraciones realizadas por los informantes. En consecuencia, quedaron fijados dos grupos, que coinciden tanto en tiempo como situación o dominio político. En un grupo se analizaron las fichas correspondientes al periodo republicano, en el que la justicia republicana tomó declaración a los distintos protagonistas con el fin de juzgar los hechos. Por otro lado, tras la victoria de Franco y en el marco de la Causa General, se volverían a juzgar los hechos; se utilizaron en este proceso aquellas primeras declaraciones y se incorporaron otras de algunos de los sobrevivientes, pues muchos de los declarantes perecieron durante la guerra, en muchos casos víctimas de la represión.

Esta fase en la investigación fue fundamental pues no sólo permitió ordenar la información, sino que posibilitó contrastarla, ya que versa sobre los mismos hechos pero en distintos momentos y, sobre todo, bajo distintas circunstancias. Gracias a ello, se ha favorecido que el historiador se acerque con mucha mayor certeza a la realidad de lo acontecido.

I. El franquismo elaboró un complejo entramado legal durante y después de la Guerra Civil con el objetivo de depurar responsabilidades dentro del bando republicano. La Causa General fue parte de este entramado. Se inició al finalizar la Guerra Civil para perseguir y juzgar los delitos cometidos en la zona controlada por la República durante la guerra. 
Otro archivo utilizado fue el de Vicus Albus (Asociación de Investigación Histórica de Vicálvaro), donde se encuentran, entre otros documentos de gran valor, las actas del Ayuntamiento de Vicálvaro durante la Guerra Civil. El magnífico trabajo de recopilación documental de dicha asociación ha sido y seguirá siendo de gran utilidad para los historiadores.

La prensa escrita fue valorada y utilizada como fuente, al igual que la historia oral. Debe señalarse que ambas pronto se mostraron claramente insuficientes, como consecuencia de la escasez de informantes y de notas referenciadas sobre Vicálvaro. En concreto, la historia oral es un recurso que podría proporcionar mejores resultados, pero el miedo y el dolor sembrados durante la guerra y la posguerra lo han imposibilitado. Aun así, las fuentes orales y de prensa han aportado valiosa información a esta investigación y han permitido contrastar algunos de los hechos en cuestión.

Las fuentes secundarias obviamente han sido fundamentales, no sólo por su aportación directa al artículo, sino por la imprescindible labor de formación y contextualización del propio historiador. Aun así, la intención principal ha sido que los protagonistas, los actores que forjaron aquellos hechos, aportaran la información directamente a lo largo del artículo, siempre que esto diera y no restara comprensión al texto. De esta forma, se ha priorizado que la información aparecida en las obras referenciadas en el artículo sea consecuencia de los testimonios de aquellos que fueron protagonistas directos durante el conflicto, como es el caso destacado de Vicente Rojo, así como de otros que tuvieron contacto directo con dichos intérpretes de aquella dolorosa realidad, como Luis Romero.

En cuanto al análisis de la información, se han establecido dos niveles que se han ido intercalando en función de las necesidades de la investigación. Así, los aspectos generales, los grandes acontecimientos que tuvieron lugar durante el estallido de la Guerra Civil española, han sido confrontados 
con los relatos de los protagonistas de los hechos de Vicálvaro. Hay un nivel macro-: el plan de Mola y Fanjul para Madrid, y su inserción dentro del golpe general; y un nivel micro-: los acontecimientos que están directa y estrechamente relacionados con lo acontecido en Vicálvaro entre el 17 y el 20 de julio de 1936.

A su vez, es obvio que los hechos ocurridos a nivel nacional influyeron obligatoriamente en lo local. Así, la investigación tiene un componente deductivo, pues no es posible entender julio de 1936 en Vicálvaro si no se conoce el contexto en el que se produjeron los hechos. Sin embargo, en este artículo la intención es desmitificar o, al menos, sembrar dudas respecto a las conclusiones generales sobre aquel conflicto, que son asumidas como "verdad" por amplios sectores.

\section{Vicálvaro}

En el mismo lugar en el que hoy se ubica el campus de la Universidad Rey Juan Carlos en Vicálvaro, se produjeron ciertos acontecimientos que han sido incomprensiblemente olvidados. Entre las paredes de esos edificios se vivieron meses de conspiración, semanas de nerviosismo y días de máxima tensión.

El lugar, entonces cuartel, era el edificio civil más importante de Vicálvaro y, como se verá en las siguientes páginas, concentró toda la tensión acumulada y fue testigo del estallido de esta durante los días en cuestión.

En realidad, los días 18, 19 y 20 de julio de 1936 fueron frenéticos en toda España. Probablemente nunca en la historia se había concentrado más tensión y actividad en todo el territorio nacional al mismo tiempo. Los acontecimientos de Barcelona y Madrid centraron el éxito de la defensa republicana, mientras que los de Navarra, las islas, Sevilla y la actual Castilla y León supusieron el apuntalamiento de 
los militares rebeldes; fueron la catapulta que transformó el golpe en guerra.

Ciudades, pueblos, barriadas, todo el territorio se vio convulsionado durante esos tres días, todos se posicionaron de un lado u otro. Hubo muertos, heridos, persecución, venganzas y un falso vacío: el hecho de que el Estado se viera "superado" por los acontecimientos no dio paso a la nada ni a la anarquía, sino a la explosión de tensiones acumuladas durante meses, años; tensiones que estallaron en violencia vergonzosa en todos los casos, con la diferencia, no menor, de que fue fomentada por los más altos responsables rebeldes, aunque dolió con mucha intensidad en los dirigentes republicanos.

Madrid fue protagonista durante toda la guerra. Su defensa sigue siendo parcialmente incomprendida, rememorada como el triunfo que finalmente no fue, porque se trata de un acontecimiento de difícil comprensión si no se le incorporan las variables casualidad y, sobre todo, valor. Barcelona puede presumir de compartir la máxima intensidad con la que se vivieron los días 18, 19 y 20 de julio, días en los que Madrid, por su parte, se convirtió en un escenario tópico de lo español, valleinclaniano, un lugar donde los milicianos tomaban vino en tascas cercanas, minutos antes de asaltar el cuartel de la Montaña.

Pero Madrid no fue sólo el cuartel de la Montaña y el general Fanjul. Hubo más: un complot amplio que fracasó estrepitosamente gracias a su pésima organización y a la entrega, in extremis, de armas por parte del Gobierno al pueblo, a los ciudadanos que decidieron defender la República frente al Ejército y las fuerzas conservadoras.

Uno de los puntos que seguramente tenía señalados en el mapa el general Fanjul era el cuartel de artillería ligera de Vicálvaro, situado en dicho pueblo a escasos 10 kilómetros del centro de la ciudad. Este cuartel, junto con otros como el campamento de Carabanchel, tenía que sublevarse y, pre- 
visiblemente, lanzar columnas sobre la capital, confluyendo bien en la montaña o en otro punto céntrico.

Hoy sabemos que el plan falló, pero desconocemos qué ocurrió en estos puntos que Fanjul y Mola miraban en el mapa, suspirando por su alzamiento y marcha sobre Madrid. Gracias a la digitalización de documentación por parte del Centro Documental de la Memoria Histórica tenemos acceso público a miles de documentos de la época, lo que nos permite reconstruir parte de los acontecimientos. A su vez, las entrevistas y otro tipo de documentación privada permiten acercarnos, con garantías, a la reconstrucción de lo sucedido durante los días 18, 19 y 20 de julio en Vicálvaro.

La destacada participación de Vicálvaro en la Guerra Civil no terminó el día 20 de julio. Tanto el pueblo como sus individuos siguieron protagonizando acontecimientos reseñables durante los 3 años de la guerra. Sus vecinos lucharon encuadrados en el Batallón Pueblo Nuevo-Ventas y en la columna Mangada, cayeron en Peguerinos en los primeros meses del conflicto, y en Ciudad Universitaria, Brunete o el frente de Valencia, al tiempo que recibieron invitados tan "ilustres" como al propio Miaja o dieron la bienvenida al "infierno" de Madrid a las Brigadas Internacionales el día 6 de noviembre de 1936, a escasas horas de entrar por primera vez en combate en Ciudad Universitaria.

En los momentos previos a la batalla del Jarama, Miaja y otros comandantes republicanos, salvo Rojo, contemplaban como principal hipótesis la posibilidad del ataque de los nacionales por el eje Vallecas-Vicálvaro, por lo que concentraban en ambos pueblos a la XII Brigada Internacional, y un poco más tarde a la $5^{\text {a }}$ Brigada Mixta (Ramírez, 2007). Su posición estratégica, cercana al "teatro de operaciones" que fueron los alrededores de Madrid, y el hecho de acoger el cuartel de artillería, situaron definitivamente a Vicálvaro en el mapa de la Guerra Civil española. 


\section{El preludio}

Para el 17 de julio de 1936, Vicálvaro contaba con una amplísima extensión municipal que englobaba buena parte de los barrios de Moratalaz, Ventas, Pueblo Nuevo o El Carmen. El Casco, que constituía en aquel entonces el actual Vicálvaro, contaba con los elementos protagonistas del primer tercio de la España del siglo Xx: las tierras de labranza, el convento, la fábrica de cemento con una línea de ferrocarril asociada a su actividad, el cuartel militar, sedes sindicales (Unión General de Trabajadores -UGT-), etc. No era Vicálvaro un pueblo que destacara por su riqueza; más bien, sus vecinos vivían con humildad material y cultural perceptibles. De hecho, la presencia de la iglesia y del convento demuestra el peso que estas instituciones tenían en la vida cotidiana del barrio, frente a un Estado mínimo e insuficiente para mejorar sustancialmente las condiciones en las que vivían los vicalvareños.

El pueblo poseía una vida económica basada en el sector primario, en la agricultura y la ganadería, y con un claro componente machista bien fundamentado en el desempeño y control de la actividad económica:

Nosotros entonces, cuando se murió mi padre, teníamos ganado, ovejas y cabras. Pero claro, cuando se murió, en el [año] treinta y cinco, pues yo tenía diez años, y el tío José Mari [...] siete. Entonces, como no se podía llevar [la leche al cerro], porque mi padre llevaba la leche al cerro del tío Pío, al puente de Vallecas, [...] pues las tuvimos que vender [las vacas]. Entonces nos vinimos a la calle Real. Luego ya la guerra nos pilló aquí, toda la guerra en la calle Real (entrevista personal, 20l0).

La presencia de un único negocio hostelero digno de ser llamado "bar" es buena muestra del nivel socioeconómico que se vivía en el pueblo, alejado de los ilustres cafés o los 
restaurantes de época que teñían de clase y vida las calles céntricas del Madrid de 1936:

Domingo Sepúlveda era concejal en el Ayuntamiento, era dueño del bar Madrid, del antiguo bar Madrid. Eran dos hermanos, Genaro y él, los dueños del bar, los dos. Ese era el mejor bar que había en Vicálvaro, los demás eran todas tabernuchas. Ese bar estuvo abierto toda la guerra. Claro, Domingo Sepúlveda, ese fue teniente de alcalde (entrevista personal, 2010). ${ }^{2}$

Mientras, el clima político del pueblo seguía el mismo camino que en el resto de España, con un aparente predominio de las organizaciones de izquierda, y de entre estas parece claro que la UGT llevaba la delantera sobre el resto, al menos hasta la primavera de 1936. Es destacable también, respecto a este contexto, el momento de la fusión de la Federación de Juventudes Socialistas con la Unión de Juventudes Comunistas de España, lo que asestó un importante golpe a las bases de influencia caballerista en su pugna con Prieto por controlar el Partido Socialista Obrero Español (PSOE) (Graham, 1991). ${ }^{3}$

En Vicálvaro había en un primer momento miembros de las Juventudes Socialistas Unificadas, con elementos procedentes de la UGT y, por lo tanto, del área de influencia de Largo Caballero. En consecuencia, tuvieron que convivir los distintos grupos de la izquierda, viéndose el pueblo claramente influido por los derroteros políticos que el transcurso de la guerra fue marcando. Vicálvaro pasó de tener concejales republicanos, socialistas e independientes, en 1932,

2. Domingo Sepúlveda Cobos fue nombrado consejero del Ayuntamiento de Vicálvaro el 31 de julio de 1938, siendo elegido tercer teniente de alcalde por catorce votos a favor y uno en blanco, según el "Acta de la sesión ordinaria de 31 de julio de 1938", en el Libro de Actas de Sesiones del Ayuntamiento.

3. Graham explica cómo los grupos fieles a Largo Caballero (izquierda socialista) e Indalecio Prieto (centristas) estaban abiertamente enfrentados, desde los acontecimientos de Asturias de 1934, por el control del PSOE. 
a contar, en 1938, con socialistas, comunistas, miembros de izquierda republicana, la Confederación Nacional del Trabajo (CNT) y Juventudes Socialistas Unificadas (JSU), cuando menos, según las actas de 1938 de las sesiones ordinarias del Ayuntamiento ("Actas de las sesiones ordinarias de 1938", s/f).

Por las entrevistas realizadas (Manzano y López-Plaza, $2011)^{4}$ y la información recabada por otros medios, se sabe que la "temperatura" subió en función de la cercanía de las elecciones de febrero de 1936. Tanto la visita de Gil Robles a Vicálvaro durante la campaña electoral, quien fue despedido entre lanzamientos de verduras y frutas, como el malestar creado durante la salida de las monjas en coches de Acción Católica para ejercer el derecho al voto, fueron dos claras muestras de que Vicálvaro estaba afectado por la política con letras mayúsculas, y resulta ahora perceptible que el pueblo no podría escapar de la orgía de sangre que se desencadenaría pocos meses después.

En contra de lo que se ha dado a entender o ha sido insinuado por algunos historiadores, la victoria del Frente Popular no puede ser vista como el punto de inflexión o de no retorno respecto a la Guerra Civil. Es cierto que las elecciones de febrero muy posiblemente exacerbaran las aspiraciones de los colectivos más desfavorecidos y marginados, y que estas aspiraciones de los trabajadores ya no podrían ser satisfechas plenamente por posturas centristas o moderadas, aunque llegaran desde el PSOE (Beevor, 2005, p. 72). Igualmente, entre febrero y julio se produjeron actos violentos y asesinatos que crearon alarma social, pero que por sí solos en ningún caso fueron suficientes para provocar

\footnotetext{
4. Andrés Manzano y Cipriano López-Plaza cuentan cómo la visita de Gil Robles en campaña con la Confederación Española de Derechas Autónomas (CEDA) y la salida de las monjas a votar en las elecciones de 1936 fueron hechos tomados a mal por amplios sectores del pueblo.
} 
un levantamiento popular. Este sólo se produciría en todo el país como reacción al golpe perpetrado por los militares.

Los actores que protagonizaron aquellos hechos son piezas imprescindibles para entender el clima que se vivió en Madrid meses antes de la sublevación militar. Meses después del golpe de julio, el capitán Joel Graña Maceiras declaró que:

En abril, con ocasión del entierro del alférez Sr. Reyes, asistió [el capitán Graña Maceiras], como casi todos los compañeros, alumnos de la escuela, tomando parte activa en el tiroteo. Pocos días después..., se incorporó a su unidad y tomó el mando de la $5^{a}$ Batería. Estando acuartelado con ocasión de los sucesos de Alcalá, les fue traída una carta de sus compañeros, [...] recordando acababa la carta diciendo: "La guarnición de Madrid, tiene la palabra". El coronel don Manuel Thomas Romero ordenó tuviese preparadas dos baterías para ir a Alcalá en plan [de] unirse al acuartelamiento, pero sin duda, enterado el Gobierno de estos propósitos, ordenó el cese del acuartelamiento, obligando [a] salir del cuartel a los oficiales. El día $I^{\circ}$ de mayo, por la tarde, comenzaron a pasar obreros en camionetas cantando y levantando el puño y, según le comunicó un soldado, les habían insultado llamándoles borregos; en vista de ello, salió solo, siendo groseramente insultado al acercarse a la camioneta y, con el fin de amedrentarlos, hizo un disparo al aire con su pistola, arrancando esta inmediatamente; enterados los generales Miaja y Cardenal de lo ocurrido, ordenaron al coronel que impusiera un arresto, a lo que se negó este diciendo que antes entregaba el mando del regimiento, quedando el incidente, por fin, en una represión privada (Declaración de Joel Graña Maceiras, 1940).

El cuartel de artillería ligera sería el escenario en el que se desarrollarían los actos correspondientes al inicio de la contienda. Su existencia ha marcado decisivamente la del pueblo y, lógicamente, no hizo menos durante aquellos momentos trascendentales. 
No cabe duda que el clima que se vivía era, cuando menos, tenso. De esta declaración se puede concluir, sin embargo, que la reacción del militar no fue proporcional a la provocación de los "obreros" en las camionetas. Tampoco fue proporcional la reacción del coronel del cuartel de artillería de Vicálvaro, quien puso a disposición su puesto como comandante de la guarnición y se negó a cumplir una orden de sus superiores. Sin duda, eran claros los síntomas que indicaban que dentro del Ejército se estaba preparando una traición que se consumaría meses después. La condescendencia de los mandos militares y de los gobernantes facilitó la organización de la sublevación.

A pesar de estos antecedentes, parece que entonces nadie pensaba en que pocos meses después ineludiblemente se iba a desatar un conflicto que duraría 3 años, con un vergonzoso costo de vidas humanas. Acierta Santos Juliá en su convencimiento de que la guerra era una de las potenciales consecuencias del clima poselectoral que se vivió en España, pero no la única posible (Juliá, 1996). La guerra no se produjo por un "destino fatal", sino por un golpe de Estado que "prendió la mecha" de una violencia que seguro superó lo imaginable hasta ese momento.

A las 17:00 horas del 17 de julio de 1936, se pasó la línea de no retorno. Un pequeño grupo de oficiales tomó la iniciativa en Melilla, deponiendo al comandante militar, general Romerales, quien pagaría con su vida el permanecer leal al Gobierno legítimo de España (Rojo, 2010, p. 99).

Mientras en la parte africana de España se encendía la mecha, en la península los acontecimientos parecían caminar lento, fruto de la confusión y de la inoperancia gubernamental. Pero la pólvora prendía y resquebrajaba el mapa nacional, de Casares Quiroga a Giral, en apenas setenta y dos horas, con tres presidentes del Ejecutivo y tres estrategias distintas: el primero tan sorprendido como inoperante; el segundo, Martínez Barrio, prácticamente 
nonato, bienintencionado pero absolutamente miope; y el tercero atendiendo una sola posibilidad: armar al pueblo.

La inoperancia gubernamental no fue aislada dentro de la España leal; más bien, se puede pensar que un virus atacó a todas las fuerzas clave en la defensa de la República, minando sus posibilidades de reacción rápida y eficaz.

El PSOE, cuya participación era decisiva para asegurar la gobernabilidad del país, se encontraba sumergido en una situación sintomática de disputa entre los llamados centristas e izquierdistas. A decir verdad, era una lucha entre las clientelas de Prieto, quien en ningún momento supo estar a la altura de los acontecimientos, y Largo Caballero, quien mostró infinidad de oscuros y algún aislado claro. ¿En qué se tradujo esto? Los centristas tenían la comisión ejecutiva del partido y también el control de El Socialista, mientras la izquierda tenía su fuerza operadora en la Unión General de Trabajadores, controlando también el periódico Claridad y la Agrupación Socialista Madrileña (Graham, 1991, p. 75).

\section{El 17 de julio}

Mientras aquellos que apostaban decididamente por la República se debilitaban por luchas internas o quedaban atenazados por el miedo a tomar decisiones, las fuerzas conservadoras avanzaban en su plan de derrocarla. El teniente Zaforas indica en su declaración que el ambiente en el cuartel en los meses previos al alzamiento era de completa oposición al Gobierno (Declaración de Indalecio Zaforas Román, 1940). El mismo 17 de julio recibió la orden de acuartelamiento, según informa, comenzando una serie de movimientos que se pueden reconstruir con base en las 
distintas declaraciones de los otros actores protagonistas del momento. ${ }^{5}$

Dichas declaraciones oscilan, en cuanto a los acontecimientos del día 17, en dos posiciones muy diferenciadas. Se puede comprobar cómo durante el periodo republicano los declarantes intentaron mostrar un claro desconocimiento de los preparativos y antecedentes de la sublevación, mientras que en las declaraciones de 1940 intentaron dejar clara su adhesión a la causa de los sublevados. Nada sorprendente, pues cada momento requería una actitud diferente, sobre todo de parte de aquellos cuya vida estaba en peligro.

La temperatura comenzó a subir desde el mismo día 17, fecha en que se presentó por la noche en Vicálvaro el general Cardenal, ${ }^{6}$ quien pudo ver que tanto al capitán Pomares como el teniente Zaforas iban armados, ordenándoles que se quitasen las pistolas pues la situación era normal (Declaración de Indalecio Zaforas Román, 1940).

Sin embargo, esa a parente normalidad no era tal. El soldado Francisco González Beltrán, sin saber por disposición de quién, recibió la orden de acuartelarse el día 17 de julio de 1936 (Declaración de Francisco González Beltrán, 1936). Nada más reseñable ocurrió hasta el día 19, según cuenta González Beltrán. Lo mismo aparece en una serie de declaraciones hasta llegar a la del comandante Luis Elorriaga Sartorius (Declaración de Luis Elorriaga Sartorius, 1936).

El comandante Sartorius es de los pocos que dice haber oído rumores de la existencia de un organismo denominado Unión Militar Española (UME) (Miranda, 2011), pero asegura que ignoraba sus fines y quiénes lo formaban. Testifica que sí había telégrafo y una estación de radio emisora

5. Es importante recordar que las declaraciones en las que se basa esta reconstrucción están tomadas en dos momentos muy distintos: verano de $1936-\mathrm{y}$, por tanto, bajo dominio de la República-y primavera de 1940, más de un año después de la victoria de los sublevados.

6. Se entiende que se trataba del general José Cardenal, de la I Brigada de Artillería de Madrid. 
y receptora, llevada por ingenieros, además de teléfono, siendo este un detalle no menor.

La UME fue fundamental para la organización del golpe, aunque su influencia en Madrid fue limitada, probablemente por la cercanía física del Gobierno (Romero, 1996). $\mathrm{Su}$ papel fue trascendental en la extensión de la trama, y dominó el golpe junto a los africanistas. Se había fundado en 1933 con participación del coronel falangista Rodríguez Tarduchy y estaba compuesta por oficiales -en activo y retirados- que buscaban proteger sus intereses gremiales y conspirar contra la República. Su principal aportación al golpe, además de la oficialidad militante que participó con toda determinación, fueron sus conexiones con los generales golpistas, falangistas, carlistas, de Renovación Española y de Juventudes de Acción Popular (Beevor, 2005, p. 80). No es creíble que entre la oficialidad no se tuviera conocimiento de lo que era y significaba la UME, siendo lógico que intentaran desvincularse de dicha entidad en los interrogatorios.

A su vez, y aunque no demuestre que llegara la orden al cuartel de Vicálvaro, es sabido que el general Mola envió las órdenes finales para el alzamiento por telegrama cifrado. ¿Llegaron estas directamente al cuartel? ¿Llegó la orden con intermediación del cuartel de la Montaña? No podemos saberlo, pero sí conocemos que las autoridades republicanas tenían especial interés en saber cómo había funcionado el sistema de comunicaciones previo al golpe.

El día 17 de julio de 1936, el comandante Sartorius recibió en su casa una llamada del coronel Romero indicándole que le esperaba un coche a las 11:30 en el metro de Goya, ${ }^{7}$ pues había que acuartelarse. Según testifica, una vez en el

7. Fueron varios los oficiales que recibieron la misma llamada e instrucciones y que, por lo tanto, viajaron en el mismo coche. Entre ellos, el capitán Ferrer Asin, el capitán Francisco Selgas Tornos, posiblemente el teniente Rómulo Ros Emperador, el comandante Antonio Sabater Jiménez, el teniente José María Romillo Polo, el teniente Miguel Redondo Correa, el teniente Joel Graña Maceiras y el teniente Jesús Pardo Pecho. 
cuartel pudo saber que la orden la había dado el general de división (Declaración de Luis Elorriaga Sartorius, 1936).

El día 4 de agosto de 1936, el coronel Thomas Romero (Declaración de Manuel Thomas Romero, 1936), quien comandaba el $2^{\circ}$ Regimiento de Artillería, acuartelado en Vicálvaro durante el golpe, dio su declaración y negó cualquier conocimiento de la sublevación y, por supuesto, pertenecer al movimiento. A su vez, indicó sí saber de la existencia de la UME, pero negó pertenecer a la misma y haber aconsejado a sus subordinados que se unieran a dicha organización. Interrogado al respecto, negó la existencia de civiles mujeres o jóvenes utilizados para establecer comunicaciones externas, aunque es claro que los republicanos sospechaban al respecto, pues en los archivos de la declaración hacen especial hincapié en esta pregunta con los diferentes testigos. Sorprendentemente, el coronel también indica en los mismos archivos que unos meses atrás habían llegado unos ingenieros, por orden superior, solicitando un local para instalar una estación de radio emisora y receptora, y otra óptica. Aseguró desconocer las comunicaciones que se hacían con dichos equipos. Cabría preguntarnos: ¿cómo es posible que el jefe del regimiento no supiera por qué y para qué se estaban instalando aparatos de transmisión en su acuartelamiento? Por otra parte, dice que el día 17 recibió orden del general de división de que fueran acuartelados, por motivo desconocido.

Por lo tanto, antes del golpe se habían instalado aparatos de transmisión en el cuartel sin que se supiera el motivo. Además, el mismo 17 se recibió orden de acuartelamiento sin que tampoco se conocieran los motivos de esto. El teniente Drake (Declaración de Francisco Drake Santiago, 1936) aporta una información que no encaja perfectamente con la del resto de la oficialidad. Dice en su declaración que el día 17 se enteró, por la tarde, de que estaban armando milicias en el parque de artillería. Tras hablar con otro 
compañero, a quien no identifica, ambos decidieron ir al cuartel a presentarse a sus jefes, lo que hicieron a las 17:30 horas, llegando posteriormente la orden de acuartelamiento. Gracias a él sabemos con mayor exactitud a qué hora llegó el general Cardenal, pues dice que esto sucedió una vez acuartelados, y que se reunió con el capitán del cuartel.

El día 17 se encontraba de oficial de cuartel el capitán Pomares Méndez, cuya declaración (Declaración de Joaquín Pomares Méndez, 1936) es importante para, al menos, intuir cómo iba subiendo la temperatura. Gracias a él sabemos que una vez acuartelados por orden de la división, llamó el general Miaja al cuartel para preguntar si ya habían ejecutado dicha orden, solicitando Miaja que extremaran las precauciones. Pomares Méndez dice que también estuvo en el cuartel el general de brigada Cardenal, quien preguntó por el coronel. Como no había llegado, dejó dicho que cuando lo hiciera hablara con el general de división, pero que estuvieran tranquilos, que no pasaba nada.

Resulta destacable este punto: se trata de nada menos que dos generales interesados por la situación en el cuartel, incluso personándose uno de ellos, mientras que el comandante del regimiento, coronel Thomas Romero, y casi toda la oficialidad estaban fuera del mismo.

Arturo Dávila Arcos era concejal en el Ayuntamiento de Vicálvaro y cuenta que tenían un enlace ("topo") dentro del cuartel que les informaba cómo se iban desarrollando los acontecimientos desde varios meses antes (Declaración de Arturo Dávila Arcos, 1936). Se trataba del maestro armero, quien en el momento de la declaración, 29 de agosto de 1936, se encontraba en el frente de la sierra. Otro civil, Luis Bartolomé, de quien sólo sabemos que era "empleado", declara que días antes percibieron que la relación entre la gente del pueblo y la tropa no era "normal" (Declaración de Luis Bartolomé, 1936). 
La indefinición de la situación en Vicálvaro para el día 17 encaja perfectamente con la del resto de Madrid, donde la rumorología iría haciendo subir la temperatura, pero sin llegar a un estado febril. La imperdonable falta de decisión del Gobierno de Casares Quiroga contrasta con la claridad con la que la UGT, con Largo Caballero al frente, solicitó armar al pueblo como única posibilidad de sofocar la rebelión (Arostegui, 2013).

\section{El I 8 de julio}

El sábado 18 de julio amanecía en calma, una aparente normalidad que escondía la tragedia. La mecha había prendido y el reguero se iba consumiendo irremediablemente siguiendo el camino del polvorín. La incapacidad del presidente de la república y del Gobierno se traduciría en acciones inocuas ante los alzados. La decisión que los sublevados mostrarían sería inversamente proporcional a la de los legítimos gobernantes de la nación.

Hoy sabemos que la designación de Martínez Barrio y su intento de negociar con los sublevados fueron una gran torpeza. No logró convencer "al director"' de pactar para evitar la confrontación, y perdió un tiempo preciado en que se pudo evitar que ciertas zonas del país se contagiaran por la sublevación, además que exacerbó los ya excitados nervios de los miembros de partidos de izquierda y los sindicatos, quienes reclamaban la entrega de armas. Sin llegar a formar gobierno, Azaña decidió pasarle la cartera ministerial a Giral, dando un giro brusco y decidiendo armar al pueblo ante lo obvio y desesperado de la situación.

La forma de operar de los sublevados obedeció, en la mayoría de los casos, a un plan similar. Primero se apoderaban de los edificios oficiales, prioritariamente del ayun- 
tamiento. Si no existían fuerzas militares, era la Guardia Civil, los falangistas y grupos armados de extrema derecha quienes proclamaban de forma oficial el estado de guerra. Sin embargo, si las fuerzas se demoraban en salir de sus cuarteles y los obreros se habían armado, se producía un cerco (Beevor, 2005, p. 92). Esto fue lo que ocurrió en algunos cuarteles madrileños, como el de Vicálvaro.

Vicálvaro también estaba gestando su parte de la tragedia. El día 18, su aparente calma se veía ligeramente alterada por la tensión creciente ante las noticias que llegaban de África. Se vivía con excitación tras los muros del acuartelamiento, siendo anormal el movimiento para un sábado.

Sabemos que para ese día casi todo el personal vinculado al cuartel se encontraba en su interior, al haber sido movilizados el día anterior. A su vez, de los testimonios se deduce que en los alrededores del cuartel comenzó a incrementarse la actividad. Si bien casi nadie habla en concreto del 18, parece claro que desde ese mismo día comenzaron las actividades a uno y otro lado del muro:

[...] que se tomaron todas las medidas ordinarias en todo acuartelamiento, sin tomar ninguna excepcional, $y$ transcurrieron sin mayor novedad la noche del 17, el sábado 18 y domingo 19; únicamente en estos días lo que sí observaron es que había muchos paisanos armados, que molestaban con registros al personal del cuartel que tenía que hacer servicios fuera del mismo (Declaración de Luis Elorriaga Sartorius, 1936).

El capitán Carrasco Ochoa es un poco más explícito en su declaración. Ya que se encontraba fuera gracias a un permiso, no fue hasta el día 18 que supo de la orden de acuartelamiento. Asegura que no se personó en el cuartel el mismo día 18 porque fue avisado, sin identificar por quién, que era muy peligroso atravesar las Ventas vestido de mili- 
tar (Declaración de Francisco Carrasco Ochoa, 1936). Es decir, Madrid estaba comenzando a hervir el mismo día 18.

Un detalle que no hay que despreciar es que el capitán Carrasco Ochoa había servido en Melilla. Sabido es que fue en África donde comenzó a gestarse la camarilla que lideraría el golpe, siendo el grupo de los "africanistas" decisivo en la organización y desarrollo del plan para derrocar a la República. ${ }^{9}$

El alférez medico, Vicente López Coterilla Vazquez, confirma por su parte que la tensión iba creciendo el mismo día 18. El cuartel se vio rodeado de milicianos que fiscalizaban todo lo que ocurría a su alrededor, especialmente los servicios de aprovisionamiento (Declaración de Vicente López Coterilla Vazquez, 1936).

¿Por qué desde el cuartel no se denunció este cerco? ¿Se informó a las autoridades en Madrid? Todo indica que no fue así, desprendiéndose de los testimonios de los oficiales que esta situación de vigilancia por parte del pueblo no despertó mayores inquietudes, lo cual es cuando menos extraño, más aún cuando la orden de armar al pueblo no se dio sino hasta el día 19, nombrado Giral presidente, obligado por las circunstancias y cediendo a la insistencia de las organizaciones obreras.

En ningún caso era normal que ciudadanos armados rodearan el cuartel de artillería: esto obedecía al propio desarrollo de la tragedia, a las sospechas que había sobre el cuartel. Sin embargo, y en contra de lo que aparece en la investigación de Francisco Alía Miranda (Miranda, 2011, pp. 254-255), ${ }^{10}$ nada certifica ni hace pensar que durante el

9. Es muy recomendable a este respecto la lectura del libro de Gustau Nerín (2005), La guerra que vino de África, publicado por Editorial Crítica.

10. "A las diez y media de la mañana del 18 de julio, una columna de milicias armadas (con escopetas de caza y bombas de mano hechas por ellos mismos) del puente de Vallecas, al mando de Manuel Fernández Cortinas, junto con fuerzas de asalto, tomó el cuartel de Vicálvaro, donde se encontraban acuartelados los soldados" (Miranda, 20I I, pp. 254-255). 
día 18 se produjera algún disparo o choque entre los militares acuartelados y las milicias que merodeaban.

\section{El 19 de julio}

Aquel domingo de julio, la situación se tornaba aún más confusa. El golpe no conseguía triunfar en todo el territorio, pero tampoco la República lograba imponer su legitimidad. El Ejército se convertía no sólo en el principal responsable de la tragedia que se avecinaba, sino también en la herramienta menos fiable con la que contaba el Gobierno para restablecer el control sobre todo el territorio nacional.

Hay todo tipo de opiniones sobre la formación del Gobierno de Martínez Barrio, pero conociendo las consecuencias es posible afirmar que fue un error del presidente Azaña. Un error más que se suma a la cadena que favoreció la sublevación y posterior derrota republicana.

El intento de formar un Gobierno que contentase a los golpistas y los hiciera avenirse a negociar fracasó irremediablemente. Los militares en rebeldía tenían tomada la decisión de alzarse para derrocar la República; todo o nada. No buscaban un cambio de rumbo: el objetivo era la victoria. Además, el Gobierno se formó sin socialistas, por negativa de estos, lo que restó apoyos y capacidad de maniobra al mismo, agravando todavía más su situación.

Por otro lado, prácticamente todas las declaraciones de los oficiales del $2^{\circ}$ Regimiento de Artillería Ligera en Vicálvaro coinciden. Según ellos, el día 19 transcurrió sin grandes novedades. Pero ¿las hubo?

Sus declaraciones parecen coordinadas. La narración de los acontecimientos es ambigua, lo que puede obedecer a una estrategia colectiva de los oficiales con el fin de salir lo mejor parados del proceso judicial que se avecinaba. Aun así, no deja de ser extraño que ni uno solo de ellos hiciera referencia a lo que estaba sucediendo en su entorno ese 
mismo día 19, cuando ya era sobradamente conocida la sublevación del ejército de África y de otros destacamentos peninsulares.

En contraste, sí hacen mención continua de que ya el 18 la ciudadanía merodeaba el cuartel, información que no encaja perfectamente con la del entonces teniente coronel Vicente Rojo, quien no establece estas actuaciones de control hasta el día 19, una vez que el Gobierno de Giral ordenó la entrega de armas al pueblo:

Inmediatamente se constituyeron, armadas bajo responsabilidad de los partidos políticos y de las [asociaciones] sindicales, diversas unidades de milicias que se apostaron unas frente a los cuarteles, cuya actitud se estimaba dudosa, y otras en los accesos a Madrid desde Campamento y los cantones de Alcalá y Vicálvaro (Rojo, 2010, p. 107).

Lo cierto es que las sospechas de que se iba a producir un golpe de Estado eran generalizadas, por lo que no causa sorpresa que organizaciones obreras y partidos se prepararan para hacerle frente, y que desde el mismo día 18 se lanzaran a las sedes gubernamentales y calles en busca de información y respuestas. El dirigente de la central obrera más importante del momento, la UGT, había advertido que una sublevación militar era posible desde la primavera de 1936 (Arostegui, 2013, pp. 471-472).

Sí es novedad, sin embargo, que en el cuartel los preparativos del día 19 consistieran en municionar cuatro baterías, preparándolas para salir si así era ordenado, informando el coronel a la oficialidad que se unirían al movimiento con el regimiento de artillería a caballo, comandado por el coronel Cañedo Arguelles, ${ }^{11}$ a cuyas órdenes se situaba el coronel 
Romero por derecho de antigüedad (Declaración de Joel Graña Maceiras, 1940).

Aunque no contamos con el dato contrastado, se puede deducir que Vicálvaro tuvo conocimiento de los acontecimientos en Campamento y Carabanchel, donde también se sublevó el Ejército con derramamiento de sangre. El general García de la Herrán había sido designado como jefe de los sublevados en los cantones militares de Madrid, entre ellos Vicálvaro (Romero, 1976, p. 467). El plan consistía en salir con sus tropas al encuentro de los sublevados en el cuartel de la Montaña, pero la lealtad de los aeródromos de Getafe y Cuatro Vientos, más la de buena parte de la tropa y suboficiales, unido esto a los milicianos, hizo fracasar esta parte del golpe, cayendo muerto el general García de la Herrán. ${ }^{12}$

Con el control sobre Campamento por parte de las fuerzas leales, la situación en Madrid se clarificaba, quedando sólo una gran duda sobre el mapa de la ciudad: la Montaña.

En paralelo, en el cuartel de artillería N. ${ }^{\circ} 2$, los oficiales eran los más proclives al alzamiento; de hecho, se percibe que entre los capitanes y tenientes no había dudas al respecto, destacando el capitán Ferrer, quien se encargó de señalar a sus compañeros de armas que el cuartel se encontraba sublevado (Declaración de Indalecio Zaforas Román, 1940), aunque esta declaración no fue acompañada de medidas ofensivas sino defensivas. Los acontecimientos que se estaban sucediendo en otros puntos de la ciudad y cantones no animaban a ninguna aventura extramuros. Esos mismos muros cada vez sentían reflejada la sombra de más milicianos al acecho que no se limitaban a rodear el cuartel, sino que lo sometían a una rigurosa vigilancia y "fiscalización" de su entorno. Todas las personas que

12. No es un detalle menor la caída de García de la Herrán, pues se trataba del número tres de la sublevación en Madrid, tras Villegas y Fanjul. Teniendo en cuenta que Villegas finalmente no siguió el plan establecido, puede decirse que era el número dos, tras Fanjul. 
entraban o salían del cuartel eran registradas, como indican varios testimonios (Declaración de Vicente López Coterilla Vazquez, 1936).

En apariencia, hasta la noche del 19 todavía no se había atravesado el punto de no retorno en Madrid. Todavía existía la posibilidad, remota, de reconducir la situación. Las milicias que patrullaban las calles no parecían mostrarse violentas; los cuarteles estaban vigilados, pero no asediados. De hecho, el propio Fanjul entra en la Montaña el día 19 hacia el mediodía (Romero, 1976, p. 341), lo que deja claro que el que iba a ser el eje del alzamiento en Madrid no se encontraba sometido a una rigurosa vigilancia, a pesar de haberse negado a facilitar los 40000 cerrojos de fusil que albergaba en su armería.

Podemos imaginar cómo en Vicálvaro la situación era de tensa espera. Tanto dentro como fuera del cuartel, se esperaban noticias de Madrid, siendo el pueblo subsidiario de su destino. Todos sabían que lo que ocurriera en la capital sería decisivo para el pueblo. Entonces, surge la pregunta: ¿estarían los mandos militares del $2^{\circ}$ Regimiento de Artillería Ligera al tanto de los acontecimientos?

\section{El 20 de julio}

La noche del 19 al 20 de julio, pocos militares del cuartel pudieron conciliar el sueño, y aquellos que sí lo lograron se vieron sorprendidos, alrededor de las 3:00 horas, por una llamada dirigida al teniente Sebastiá. El oficial de guardia de intendencia del acuartelamiento situado en el barrio de Pacífico le avisaba que frente a su destacamento pasaban camiones repletos de milicianos que gritaban "A por los de Vicálvaro" (Declaración de Joel Graña Maceiras, 1940).

No consta que los milicianos atacaran el cuartel, ni que los soldados intentaran salir, pero sí que se intensificó el cerco a su perímetro, lo que generó una situación de máxima 
tensión durante cuatro largas horas, hasta las siete de la mañana, cuando cayó la primera de las bombas sobre el acuartelamiento. Según se desprende de la declaración del capitán Graña, no hubo provocación previa: esa bomba pareció caer de la nada. Sin embargo, sí se dio la orden de disparar desde el cuartel contra el aparato aéreo, situación que se alargó hasta las 11:00 horas (Declaración de Joel Graña Maceiras, 1940).

Agustín Sanz García, ${ }^{13}$ empleado del ayuntamiento de Vicálvaro, declaró que dos aeroplanos se presentaron alrededor de las 7:00 horas del día 20, lanzando dos bombas que cayeron fuera del cuartel e incendiaron dos eras. En su declaración, confirma que comenzó un intercambio de disparos con milicianos, sin recordar si desde el cuartel se disparó antes o después de iniciado el bombardeo (Declaración de Agustín Sanz García, 1936).

No existía orden de alzamiento definida, no hubo día y hora fijos para que todos los implicados en el golpe se alzaran (Miranda, 2011, p. 105), de ahí que la situación en Vicálvaro, al igual que en otros cuarteles como la mismísima Montaña, estuvieran en una tensa espera.

Con la llegada del mediodía, se comenzó a aclarar el panorama. Al tiempo que en el resto del país se tomaba conciencia del fracaso de la intentona golpista, los bombardeos sobre los cuarteles madrileños tuvieron un efecto desmoralizador (Rojo, 2010, p. 137). A su vez, el Gobierno decidió despejar la duda que suponía el cuartel de la Montaña, organizando fuerzas que lo rodearon y asaltaron, con lo que quedó resuelta la "ecuación” para el mediodía del día 20.

13. Era conocido con el alias de "el Cohete". 


\section{Figura 1. Bando de guerra del general Fanjul}

El Ejercito español, dispuesto a salvar a España de la ignominia y dispuesto a que no sigan gobernando bandas de asesinos ni organizaciones internacionales, toma por plazo breve la dirección política de España, con el exclusivo objeto de mantener el orden público y el respeto a la propiedad y a las personas. Para la eficacia de este propósito, yo, general de División, tomo el mando de la Primera orgánica del Ejército y

\section{ORDENO Y MANDO:}

Artículo $1^{\circ}$. Queda declarado el estado de guerra en todas las provincias de Castilla la Nueva, dependiendo de mi autoridad todas las fuerzas armadas y todos los organismos políticos y administrativos del Estado.

Artículo $2^{\circ}$. Se prohíbe la formación y circulación de grupos de más de tres personas, los cuales serán disueltos por la fuerza si se resistieran a la primera intimación.

Artículo $3^{\circ}$. Serán considerados como rebeldes o sediciosos los que traben combate con la fuerza pública y cuantos, uniformados o sin uniforme, lleven armas.

Los porteros serán considerados como autores de auxilio a la rebelión cuando hayan permitido la entrada en las fincas a personas que hayan realizado acto de agresión a la fuerza pública.

Artículo $4^{\circ}$. Queda prohibida la publicación de todos los periódicos y revistas, de cualquier clase que sean, necesitando para aquella permiso expreso mío. Las radios no publicaran más noticias que las que ordene $\mathrm{mi}$ autoridad, y al principio y al fin de sus emisiones transmitirán la Canción del Soldado.

Artículo $5^{\circ}$. Todos los delitos contra las personas, contra la propiedad o la fuerza pública, cualquiera que sea la calidad de quien los cometa, estará sometido a los preceptos del Código de Justicia Militar de 1930, considerándose como delitos de lesa patria y juzgados en juicio sumarísimo. Artículo $6^{\circ}$. Se constituirá en esta División, con carácter permanente, un Consejo de Guerra para juzgar y condenar a quienes realicen actos de los indicados, y a los que no han sentido en el fondo de su alma el santo estímulo de la defensa de España.

Artículo $7^{\circ}$. Quedan prohibidas todas las reuniones, mítines, conferencias, manifestaciones públicas y juntas generales que no reciban autorización expresa de mi autoridad.

Artículo $8^{\circ}$. Quedan disueltos todos los Sindicatos marxistas, que serán clausurados, incautándose el Gobierno de la documentación.

Artículo $9^{\circ}$. Se declaran incautados y a mi disposición todos los automóviles de carga, viajeros y particulares; motocicletas y vehículos de todas clases, quedando prohibida toda circulación rodada en el interior de las poblaciones y en las carreteras mientras los conductores no se provean de la licencia especial desde las diez de la noche, solo circulará la fuerza pública.

Artículo $\mathbf{1 0}^{\circ}$. Las fuerzas de Policía y demás cuerpos dependientes de la Dirección General de Seguridad serán consideradas como fuerzas del Ejército, poniéndose a mis órdenes.

Para evitar un día de luto al pueblo de Madrid, espero que todos colaboraran a la obra de patriotismo que inicia el Ejército, quien no sale de sus cuarteles combatiendo a ningún régimen sino a los hombres causantes de la situación actual, que lo han deshonrado.

Exhorto a todos los obreros a que mantengan una actitud patriótica de acatamiento, porque este movimiento tiende, en primer término, a librarlos de la dictadura de los hombres que les rigen, y que les están sumiendo en la mayor miseria. ¡Tened presente, obreros españoles, que el Ejército, cuya masa sale de vuestras filas y por cuyas venas corre vuestra sangre, no os abandonará en la obra de justicia que hay que realizar!

¡Viva España! ¡Viva la República! ¡Viva el Ejército!

Joaquín Fanjul

Fuente: Venero (1967, pp. 306-307). 
Es muy probable que se diera un efecto dominó en la situación de dicho día que tuviera como consecuencia la rendición del cuartel de Vicálvaro. La situación del golpe el día 20 afectó directamente a las posibilidades de éxito de los militares y falangistas acantonados en el cuartel de la Montaña. La imposibilidad de ejecutar un plan de columnas que avanzaran sobre la capital hizo insostenible la posición de Fanjul, rodeado por miles de milicianos:

El general Fanjul, militar con prestigio, españolista y valiente defensor de sus ideas derechistas, se ha mostrado en todo momento animoso, ha dado impresión de seguridad, ha prometido ayudas: una columna que al mando del general Mola ha llegado a la Sierra y avanza a marchas forzadas sobre Madrid, otra columna con fuerte artillería que viene del campamento de Carabanchel (Romero, 1976, p. 545).

Pero las columnas fueron detenidas en la sierra, Fanjul cayó herido y el cuartel fue tomado por asalto. La Montaña desaparece del mapa de los sublevados, quedando Madrid descabezada y, por lo tanto, fuera de su influencia. Un gran revés para los golpistas, definitivo para las pocas esperanzas que albergaban en la capital.

Las declaraciones de Fanjul ante las preguntas del fiscal parecen encaminadas a crear confusión sobre su papel en el golpe. De poco le serviría, pues horas después, el día 17 de agosto, sería condenado a muerte y fusilado:

Fiscal. (F) - ¿Luego niega que estaba en rebeldía contra el Poder público? Fanjul. (P) - Insisto en que mi rebeldía era tan sólo de espíritu ( $L a$ Libertad, 1936).

Al ser cuestionado sobre por qué obedeció las órdenes del general Villegas, como había indicado en un principio, respondió que Villegas no podía darle tales órdenes: 
F.- ¿Quién podía darle tales órdenes?

P. - El general Mola.

F.- Si el general Mola no era su superior, ¿cómo podía darle órdenes?

P.- Porque podía...

F.- ¿Como jefe de la rebelión militar?

P.- Sí, claro.

F.- ¿Pues no aseguraba el procesado anteriormente que no se había rebelado nada más que espiritualmente? ¿Estaba o no de acuerdo para la rebelión?

P.- - Sí, claro; yo... sabía algo de la rebelión; pero yo no era el jefe.

F.- ¿Dio órdenes a otras fuerzas de la guarnición de Madrid?

P.- No; hablé por teléfono con algunos cuarteles, pero no di ninguna orden para la sublevación (La Libertad, 1936).

A pesar de la incoherencia del general Fanjul, su declaración no termina por negar con rotundidad su participación en la rebelión. Más sorprendente es la del coronel Fernández Quintana:

Fiscal. (F) - Puso u ordenó poner bandera blanca -para evitar más derramamiento de sangre inútil...- ¿Inútil para quién?

Coronel. (P)— Para nuestra causa.

F.- ¿No dijo antes el procesado que su causa era la defensa del régimen y la República?

P.-Es que nosotros creíamos que el Frente Popular se había levantado contra el Gobierno (La Libertad, 1936).

Resulta prácticamente imposible creer que los sublevados en la Montaña confundieran con una sublevación la defensa de los milicianos del régimen republicano.

Las declaraciones de Fanjul, Villegas o Quintana son importantes porque muestran cómo intentaron camuflar su adhesión a la rebelión. Podría interpretarse que cuando se trata de salvar la vida, el honor y la verdad pierden su fuerza. En este mismo contexto, parece inverosímil que el 
coronel Thomas se dejara engañar por el director general de seguridad, ${ }^{14}$ quien le indicó que el propio Azaña estaba con ellos y se iban a organizar unos batallones para desarmar a los milicianos (Declaración de Joel Graña Maceiras, 1940).

Los hechos en Vicálvaro corren paralelos a los de Madrid. A diferencia de la Montaña o Campamento, ¿hubo unidad de acción dentro del cuartel de Vicálvaro? Conocemos que la República mantuvo importantes lealtades entre el generalato y el cuerpo de suboficiales y tropa, pero padeció la escasez de oficiales capaces de dirigir las tropas en el campo de batalla. En el cuartel, fueron los oficiales los más entusiastas con el alzamiento, encabezados por el capitán Ferrer. Sin embargo, entre los suboficiales había algunos leales a la República que pudieron ser decisivos para que no se produjera un baño de sangre:

Que en la madrugada del lunes 20, el capitán Sr. Ferrer, despertó a la tropa, ordenándole se colocara en las ventanas del edificio al servicio de las ametralladoras; que más tarde, al volar sobre el cuartel unos aeroplanos, recibieron la orden de continuar en las posiciones y armados de mosquetones, para hacer fuego, en su caso, contra los aeroplanos, como así se hizo al lanzar estos la primera bomba contra el cuartel, recibiendo más tarde orden de los sargentos contraria a la de los oficiales, que seguían ordenando continuase el fuego, para que este cesara, como así lo efectuó el diciente y resto de la tropa y después, como la aviación siguiera bombardeando, los brigadas y sargentos que habiendo sido advertidos de lo que sucedía y quese [sic] trataba de un movimiento de rebelión contra el Gobierno, con lo cual no estaban conformes dichas clases, se colocaron banderas blancas, rindiéndose el cuartel a lasmilicias [sic] populares y al Ejército que rodeaban el mismo y que se hicieron cargo, deteniéndolos [sic] de los jefes y oficiales, y confraternizando

14. José Alonso Mallol fue director general de seguridad hasta finales del mes de julio de 1936. 
desde este momento tanto la tropa como los suboficiales y sargentos con el pueblo (Declaración de Francisco González Beltrán, 1936).

En función del rango del declarante, los acontecimientos fueron unos u otros. Mientras los oficiales pretendieron introducir confusión con sus declaraciones, los suboficiales señalaron con el dedo directamente al coronel y la mayoría de los oficiales como adeptos al golpe. Por ejemplo, el brigada Manuel Juaneda Gayan declara que el coronel les reunió $^{15}$ para comunicarles que estaba adherido al movimiento subversivo, porque había que hacer una república sana como la que él votó en 1931, argumentando que la actual era una república de terrorismo y bandolerismo. No terminó bien la reunión para el coronel y los sublevados, pues los suboficiales se negaron a unirse al movimiento. $\mathrm{Al}$ poco tiempo, el coronel ordenó reunirlos de nuevo para comunicarles que no podía tener en el cuartel a cuarenta hombres que podían hacerle traición, ordenándoles salir de dos en dos, en intervalos de tiempo. Cuando seis de ellos ya habían salido, comenzó el tiroteo provocado por el lanzamiento de una bomba desde un avión (Declaración de Manuel Juaneda Gayan, 1936).

Cuenta el brigada que los oficiales se retiraron al cuarto de estandartes, desde donde se rindieron, dando cuenta a Madrid por telégrafo de ello. Fue entonces cuando entraron unos guardias de asalto que procedieron a la detención de los oficiales y sublevados.

La declaración del sargento Sánchez Pegalajar (Declaración de Ramón Sánchez Pegalajar, 1936) va en el mismo sentido que la del brigada. Añade que el día 19, previo a la reunión del 20 con el coronel de los suboficiales, el capitán Francisco Selgas reunió a los sargentos y brigadas y les dijo que posiblemente el regimiento tuviera que salir, y que 
al que no estuviera dispuesto a ello se le pegaría un tiro. $\mathrm{Al}$ enterarse el coronel del malestar del sargento, le llamó preguntándole en el patio qué era lo que ocurría:

[...] como el declarante manifestara que él no estaba dispuesto a ir en contra del Gobierno y el coronel le dijera que mientras él fuera coronel, en su regimiento no permitiría que hubiera ningún traidor (Declaración de Ramón Sánchez Pegalajar, 1936).

A lo que el sargento contestó:

Yo no soy traidor, y recuerdo las frases que usted pronunció en el acto de jura de bandera, el 15 de febrero del año actual, diciendo que los soldados tenían que acatar a un Gobierno monárquico, si en las elecciones del siguiente día vencían los monárquicos y a un Gobierno comunista si vencieran en las Elecciones [sic] éstos, pues esta era el deber de todo militar (Declaración de Ramón Sánchez Pegalajar, 1936).

Respecto al día 20, la declaración de Sánchez Pegalajar únicamente añade a la declaración del brigada Juaneda que una vez que salió del cuartel se reunió con el teniente de alcalde de Vicálvaro, junto al cual, y con ciudadanos del pueblo, lo regresaron hasta el cuartel, encontrándose ahí con un tiroteo entre militares y milicianos que terminó con el bombardeo y rendición de los sublevados.

Por su parte, el comandante Luis Elorriaga Sartorius declara que el avión que lanzó las bombas no llevaba ningún emblema que lo identificara, cuestión que fue decisiva a la hora de ordenar hacer fuego contra el mismo. Sin embargo, señala que no fueron las bombas, sino la llamada desde la Dirección General de Seguridad indicándoles que tenían que rendirse, la que provocó que se procediera en ese sentido.

Continúa el comandante Elorriaga Sartorius indicando que no hubo arenga de ningún tipo por parte del coronel. A pesar de no haber estado presente, sí dice saber que el jefe 
del regimiento se reunió con los suboficiales simplemente para comentarles que el que quisiera marcharse podría hacerlo pues, posiblemente, tendrían que enfrentarse con el pueblo si atacaban el cuartel (Declaración de Luis Elorriaga Sartorius, 1936). En la misma línea, el coronel Thomas Romero declara que el avión que efectuó el bombardeo era comercial y no militar, por lo que dio la orden de abrir fuego. Tras hablar con el director general de seguridad, acató la orden de rendirse,

[...] poniendo el pueblo que rodeaba el cuartel sábanas blancas, ordenando el dicente que cesara el fuego, a pesar de lo cual el avión continuó, aun estando ya en el cuartel guardias de asalto, lanzando bombas, que mataron a un cabo de asalto e hirieron a otro guardia, aparte de las bajas que se habían tenido en el cuartel de tres o cuatro soldados heridos y uno muerto (Declaración de Manuel Thomas Romero, 1936).

Sobre los suboficiales, el coronel testifica que hubo algunos sargentos y brigadas que habían oído decir que en caso de que el regimiento saliera, matarían a sus familias o pondrían delante del pueblo a sus familiares.

En atención a esto, y como el dicente pensó que quizás por defensa del cuartel pudiera enfrentarse con el pueblo, llamó a los sargentos, brigadas y obreros y les dijo, por creerlo un acto de caballerosidad, que quizá tuviera el regimiento que defender el cuartel en contra de las masas y para este caso, si tenían miedo por lo que pudiera ocurrir a sus familias, que podían marcharse los que quisieran, como así lo hicieron algunos, quedándose por el contrario otros; que no es cierto que el declarante, al hablar a los sargentos y brigadas dijera se hallaba unido al movimiento, puesto que este no le conocía, aunque quizás fuera posible que él manifestara que como republicano no estaba conforme con una república soviética al parecer o comunista; y que efectivamente es verdad que ordenó [sic] la salida del cuartel de dos en dos a los que 
quisieran marcharse, con el objeto de evitar la provocación si salían todos unidos (Declaración de Manuel Thomas Romero, 1936).

El teniente Drake (Declaración de Francisco Drake Santiago, 1936) confirma que también se hizo fuego desde unas trincheras alrededor del cuartel, así como desde la que llama "casa de los cerdos", siendo este respondido por los sublevados. Confirma que, en un momento determinado, el coronel llamó a los oficiales a la sala de estandartes, donde les comunicó que suspendieran el fuego. Drake declara que tampoco escuchó la conversación entre el jefe del regimiento y los suboficiales, testificando que el coronel sabía que en el pueblo se estaba armando a las milicias, y que en previsión de un choque entre milicianos y militares permitió salir a los suboficiales para que pusieran a salvo a sus familias.

El capitán Joaquín Pomares Méndez testifica en la línea del teniente Drake, indicando que desde una casa próxima se abrió fuego, llegando incluso a impactar una bala en un lavabo en la batería del declarante (Declaración de Joaquín Pomares Méndez, 1936).

El capitán Ferranz (Declaración de Francisco Ferranz Pérez Santiago, 1936) declara que fue el coronel quien se presentó en el cuarto de sargentos alrededor de las 7:00 horas. Al haber comprobado que había personas sospechosas y armadas alrededor del acuartelamiento, dio permiso a los suboficiales para salir e incluso refugiar a las familias en el propio acuartelamiento. Afirma que salieron varios sargentos y obreros, y que algunos de ellos no volvieron a incorporarse.

Las declaraciones de los oficiales describen una situación, cuando menos, esperpéntica. Cabría cuestionarse ¿cómo iba a permitir el jefe del regimiento que la mayoría de sus suboficiales salieran de un acuartelamiento que se encontraba rodeado por milicias armadas? 
Muy importante es también que el capitán Ferranz habla de dos aviones en su declaración, uno de características de la aviación civil, pero otro militar, y de que ambos arrojaron bombas sobre el cuartel. Sin embargo, el teniente José Relanzón García Criado (Declaración de José Relanzón García Criado, 1936) vuelve a decir que sólo había un avión, y no era militar. También menciona en su declaración la salida de los sargentos para defender sus familias, indicando que sólo salieron tres o cuatro de ellos. Por su parte, el teniente Miguel Redondo Correa dice no saber si alguno se marchó, aunque le parece que sí lo hicieron dos o tres (Declaración de Miguel Redondo Correa, 1936). El capitán Francisco Selgas y Tornos va más lejos en su declaración al indicar que algunos de los sargentos sí regresaron con sus familias al cuartel, aunque otros nunca volvieron (Declaración de Francisco Selgas y Tornos, 1936).

Objetivamente, podemos saber que hubo suboficiales que abandonaron el cuartel, al parecer pocos, porque mientras se producía su salida comenzó el bombardeo de uno o dos aparatos, situación similar, por cierto, a la que se vivió en otros regimientos y cantones de Madrid, donde la labor militar aérea fue un factor fundamental para derrumbar la moral de los sublevados.

En su declaración, el teniente Carlos Sebastian Llegat indica que también escuchó que el coronel facilitó la salida de los suboficiales ante el riesgo de que la gente armada en el pueblo pusiera a los familiares de estos frente al cuartel. Junto con algunos sargentos, marcharon también maestros de taller, yéndose estos últimos hacia Madrid y siendo, según les transmitieron después algunos guardias de asalto declarantes, los que denunciaron hechos falsos en la Dirección General de Seguridad, como haber sido expulsados del cuartel, cuando en verdad salieron voluntariamente (Declaración de Carlos Sebastian Llegat, 1936). 
El factor civil fue fundamental para la República. Desde hacía tiempo, el Ayuntamiento tenía un enlace-informante dentro del cuartel: el maestro armero. En la mañana del día 20, salieron unos sargentos, entre ellos el cocinero Ramón Sánchez, que indicaron que el coronel les dijo que si no estaban de acuerdo con la sublevación, se marcharan. Acordaron pedir auxilio a Madrid, pero como el teléfono no funcionaba, el teniente de alcalde cogió un coche. Según su versión, llegó entonces un aeroplano que fue atacado desde el cuartel, y respondió este lanzando una bomba que cayó en una era y provocó un gran incendio, arruinando a dos familias. Luego hubo disparos entre milicianos y el cuartel (Declaración de Arturo Dávila Arcos, 1936).

El concejal de Vicálvaro confirma la llamada realizada por el director general de seguridad al capitán Ferrer, de la cual se enteró por su participación en el control de la central de teléfonos. Según narra, la llamada no fue cordial, sino que el director general se tuvo que valer de amenazas para conseguir la rendición del coronel. Indica que desde que se inició la sublevación hasta la rendición pasó una hora aproximadamente.

A pesar de que el capitán Ángel Ferrer es de los más relacionados con el golpe, fue él quien habló con el director general de seguridad, de quien declaró ser amigo, recibiendo de aquel la orden de rendirse.

$\mathrm{Al}$ igual que en la Montaña y en Campamento, hubo quien intentó huir del cuartel sin ser visto, pero los milicianos, y posiblemente el pueblo, ya habían rodeado el edificio, imposibilitando fugas como la del teniente de complemento Alfonso Espinosa Fernández (Declaración de Alfonso Espinosa Fernández, 1936), quien fue detenido y llevado al ayuntamiento de Vicálvaro, quedando recluido en una carbonera antes de su traslado a la Dirección General de Seguridad y después a la cárcel desde la cual declaró. Con esta y otras declaraciones, queda fuera de toda duda la 
implicación desde el primer momento del Ayuntamiento de Vicálvaro contra el golpe y a favor del Gobierno.

El bombardeo, las milicias que asediaban el cuartel, la llamada de la Dirección General de Seguridad, seguramente la confirmación de la caída de Campamento y la situación en la Montaña fueron factores en contra que provocaron que el regimiento decidiera rendirse.

El capitán Francisco Selgas y Tornos declara por su parte que, en el momento de la rendición, el teniente coronel de los de asalto entró en el cuartel con el puño en alto. Después llegó un teniente coronel de ingenieros junto con milicias armadas, llevando el puño en alto y una estrella roja de cinco puntas en el uniforme.

Varios testigos coinciden en indicar que ya rendido el cuartel, el avión siguió lanzando bombas, provocando una de ellas la muerte de un guardia de asalto, un soldado del regimiento y varios heridos.

Testigos como el teniente Joel Graña Maceiras (Declaración de Joel Graña Maceiras, 1936) también indican que el coronel ordenó situar banderas y sábanas blancas en las ventanas, lo que, a priori, debiera de haber sido suficiente para que el avión dejara de bombardear. El alférez Fernando García Ampuero testifica que el coronel dio esta orden pues a él así le fue transmitida por la Dirección General de Seguridad (Declaración de Fernando García Ampuero, 1936).

El teniente Alberto Pérez-Cosio Rubio testifica que a las 7:00 horas del mismo día 20 pudo observar cómo el cerco sobre el cuartel se había intensificado, habiendo levantado trincheras los milicianos. Añade que observó cierta coordinación entre el avión de bombardeo y los milicianos, obedeciendo a una especie de consigna, que no explica, para iniciar el fuego coordinadamente. Su descripción del momento de la rendición informa que los paisanos armados y los guardias de asalto irrumpieron en el cuartel haciendo 
saludos marxistas y gritando vivas a Rusia y a España soviética (Declaración de Alberto Pérez-Cosio Rubio, 1936).

La declaración de Luis Bartolomé ${ }^{16}$ ayuda a entender mejor la sucesión de estos acontecimientos. Cuenta que días antes percibieron que la relación entre la gente del pueblo y la tropa no era "normal". Las sospechas y la tensión aumentaron cuando salieron los sargentos y les informaron, en la mañana del día 20 de julio, que consideraban que el cuartel iba a sublevarse. Desalojaron el pueblo de mujeres y niños por temor a que fuera cañoneado desde el cuartel, y los hombres, que eran unos cuarenta o cincuenta, se prestaron a rodear el cuartel y defender el pueblo. Luis Bartolomé también declara que el teniente de alcalde telefoneó a la Dirección General de Seguridad para que vinieran unos aeroplanos para conseguir la rendición del cuartel. Indica que en cuanto apareció el avión, el fuego se inició desde el cuartel, siendo respondido por unos milicianos apostados alrededor del mismo. Confirma que una bomba cayó después de llegadas las tropas de asalto, provocando la muerte de un guardia de dicho cuerpo, y que guardias de asalto y milicianos penetraron juntos en el cuartel (Declaración de Luis Bartolomé, 1936).

\section{Conclusiones}

De esta investigación, se desprenden algunas conclusiones que no por sabidas hay que dejar de mencionar. El cuartel de artillería ligera de Vicálvaro se sublevó contra la República, formando parte del dispositivo de alzamiento en Madrid, con eje en el cuartel de la Montaña. A pesar de que las declaraciones de los oficiales intentaron en su día confundir al tribunal, y hoy buscan hacer lo mismo con el

16. De Luis Bartolomé sólo se indica "empleado" en su ficha, por lo que no es posible saber cuál era su oficio. 
historiador, la propia sucesión de los hechos, el resto de declaraciones de suboficiales y civiles, así como la ventaja que supone analizar hechos casi 80 años después, pueden llevarnos a afirmar que el cuartel era parte del golpe.

Los actores son los esperados: oficiales golpistas, generales de tímida lealtad, suboficiales fieles a su juramento, milicianos y actores secundarios de carácter civil. Un escenario completo, con todo el atrezo de la época: uniformes, aviones, ametralladoras, piezas de artillería, hoces y martillos, banderas blancas y el resto del "menaje" que se haría cotidiano durante los siguientes 3 años. Sin embargo, es destacable la poca sangre que se regó en el entorno y dentro del propio cuartel de artillería.

Habría que preguntarse: ¿por qué apenas hubo derramamiento de sangre en Vicálvaro? Había factores para ello, enfrentados de un lado el ejército sublevado y del otro los milicianos armados.

Es indudable que el golpe en Vicálvaro no tenía visos de triunfo una vez que fue abortado el golpe en la capital, pero igual de cierto es que en el cantón de Carabanchel se derramó sangre ante el intento de salida de García de la Herrán. De igual forma, en la Montaña hubo decenas de muertos y, sin embargo, en Vicálvaro apenas murieron dos soldados por una bomba de aviación, presumiblemente lanzada ya que el cuartel se había rendido.

Ese es otro factor que invita a pensar en la práctica ausencia de derramamiento de sangre. Sí se desataron las hostilidades en Vicálvaro, no fue una rendición por mera presión ciudadana. Fue necesario el uso de la fuerza para que el coronel aceptara rendir el cuartel, existiendo total ausencia de venganzas o fusilamientos sumarios. ¿Por qué no se desató una ola de violencia contra los sublevados?

Quizás la respuesta la tenga Vicente Rojo: 
Mucho se ha discutido si se debió o no armar al pueblo... pero cuando la sociedad española pueda conocer el volumen e índole de los desmanes que se cometieron en la zona donde el pueblo no había sido armado, se comprenderá que ni esos desmanes, ni la crueldad, ni el terror que se crean con el crimen incontrolado, eran cosas independientes del hecho de que el pueblo hubiera sido o no armado. La verdad es que si algunas de las armas entregadas se utilizaron en actos criminales, la mayor parte de ellas se emplearon en la finalidad que con su entrega se quería alcanzar: combatir la rebelión (Rojo, 2010, p. II5).

El pueblo en armas consiguió su objetivo: rendir el cuartel y que se procediera a la detención de los sublevados. La justicia republicana actuaría en consecuencia con los sublevados, como así hizo, sin que el pueblo de Vicálvaro optara por otro tipo de justicia paralela.

El pueblo fue armado con dicho fin, y los acontecimientos llenan de razón la decisión del Gobierno de Giral, pues sólo así se consiguió impedir el éxito del golpe en todo el territorio nacional. De hecho, los acontecimientos de Vicálvaro demuestran que el Estado republicano no desapareció, sino que se vio violentamente golpeado cuando su monopolio de la violencia saltó por los aires al ser traicionado por su principal valedor armado, el Ejército. Sin embargo un Estado es mucho más que su Ejército, que no deja de ser una herramienta a su servicio, siendo su principal y único sentido de existencia el servicio al pueblo. En este caso, se invirtieron los factores y fue el pueblo el que sostuvo el Estado, debilitado y escorado, pero no superado.

La entrada del teniente coronel de carabineros en el cuartel, tras la llamada desde la Dirección General de Seguridad, muestra claramente cómo el Estado se mantuvo en pie, obviamente gracias al pueblo, que armado pudo hacer frente a la sublevación militar.

Si la anarquía se hubiera impuesto ante una situación de vacío de poder, o se hubiera iniciado un proceso revolucio- 
nario, difícilmente las estructuras republicanas se hubieran mantenido en pie, como en verdad ocurrió.

Los acontecimientos de Vicálvaro demuestran que el golpe no fue combatido con anarquía y violencia desatada: gracias a las armas, el pueblo pudo defender el modelo de Estado por el que había optado en 1931 frente a las fuerzas reaccionarias que encontraron en el Ejército el ariete con el cual intentar derrumbar la República de un solo golpe. Como esto no les fue posible, decidieron seguir golpeando hasta dejar al pueblo agotado y rendido.

Fecha de recepción: 28 de julio de 2014 Fecha de aceptación: 26 de junio de 2015

Bibliografía “Actas de las sesiones ordinarias de 1938" (s/f). Libro de Actas de Sesiones del Ayuntamiento de Vicálvaro. Caja 63.A3. Vicus Albus. Asociación de Investigación Histórica de Vicálvaro, Madrid.

Arostegui, J. (20|3). Largo Caballero. El tesón y la quimera. Barcelona: Debate.

Beevor, A. (2005). La Guerra Civil española. Barcelona: Crítica.

Declaración de Agustín Sanz García (29 de agosto de 1936). FC-CAUSA_GENERAL, I5I8, Exp. I3, Imagen 324. Archivo Histórico Nacional, Madrid.

Declaración de Alberto Pérez-Cosio Rubio (5 de agosto de 1936). FC-CAUSA_GENERAL, I5 I8, Exp. I3, Imagen 1 19. Archivo Histórico Nacional, Madrid.

Declaración de Alfonso Espinosa Fernández (4 de agosto de 1936). FC-CAUSA_GENERAL, I5 I8, Exp. I3, Imagen 57. Archivo Histórico Nacional, Madrid. 
Declaración de Arturo Dávila Arcos (29 de agosto de 1936). Bibliografía

FC-CAUSA_GENERAL, I5I8, Exp. I3, Imagen 320.

Archivo Histórico Nacional, Madrid.

Declaración de Carlos Sebastian Llegat (5 de agosto de 1936). FC-CAUSA_GENERAL, I5 I8, Exp. I3, Imagen 86-87.

Archivo Histórico Nacional, Madrid.

Declaración de Fernando García Ampuero (5 de agosto de 1936). FC-CAUSA_GENERAL, I5 I8, Exp. 13, Imagen

134. Archivo Histórico Nacional, Madrid.

Declaración de Francisco Carrasco Ochoa (4 de agosto de 1936). FC-CAUSA_GENERAL, I 5 I8, Exp. 13, Imagen

104. Archivo Histórico Nacional, Madrid.

Declaración de Francisco Drake Santiago (4 de agosto de 1936). FC-CAUSA_GENERAL, I5I8, Exp. 13, Imagen

65. Archivo Histórico Nacional, Madrid.

Declaración de Francisco Ferranz Pérez Santiago (4 de agosto de 1936). FC-CAUSA_GENERAL, I5 I8, Exp. I3, Imagen

70. Archivo Histórico Nacional, Madrid.

Declaración de Francisco González Beltrán (3I de julio de 1936). FC- CAUSA_GENERAL, I5 I8, Exp. I3, Imagen 28. Archivo Histórico Nacional, Madrid.

Declaración de Francisco Selgas y Tornos (5 de agosto de 1936).

FC-CAUSA_GENERAL, I5I8, Exp. 13, Imagen 80-83.

Archivo Histórico Nacional, Madrid.

Declaración de Indalecio Zaforas Román (4 de mayo de 1940).

FC-CAUSA_GENERAL, I5I8, Exp. 13, Imagen II-I3.

Archivo Histórico Nacional, Madrid.

Declaración de Joaquín Pomares Méndez (5 de agosto de 1936). FC-CAUSA_GENERAL, I5 I8, Exp. 13, Imagen 104. Archivo Histórico Nacional, Madrid.

Declaración de Joel Graña Maceiras (5 de agosto de 1936). FC-CAUSA_GENERAL, I5 I8, Exp. I3, Imagen I I I-I I3. Archivo Histórico Nacional, Madrid. 
Bibliografía
Declaración de Joel Graña Maceiras (I de mayo de 1940). FC-CAUSA_GENERAL, 1518, Exp. 13, Imagen 6-10.

Archivo Histórico Nacional, Madrid.

Declaración de José Relanzón García Criado (5 de agosto de 1936). FC-CAUSA_GENERAL, I5 18, Exp. 13, Imagen 78-79. Archivo Histórico Nacional, Madrid.

Declaración de Luis Bartolomé (29 de agosto de 1936).

FC-CAUSA_GENERAL, I5I8, Exp. I3, Imagen 323.

Archivo Histórico Nacional, Madrid.

Declaración de Luis Elorriaga Sartorius (4 de agosto de 1936).

FC-CAUSA_GENERAL, 1518, Exp. 13, Imagen 4I-43.

Archivo Histórico Nacional, Madrid.

Declaración de Manuel Juaneda Gayan (3I de julio de 1936).

FC-CAUSA_GENERAL, I5 I8, Exp. 13, Imagen 32-34

y 479. Archivo Histórico Nacional, Madrid.

Declaración de Manuel Thomas Romero (4 de agosto de 1936).

FC-CAUSA_GENERAL, I5 I8, Exp. 13, Imagen 45-48.

Archivo Histórico Nacional, Madrid.

Declaración de Miguel Redondo Correa (5 de agosto de 1936).

FC-CAUSA_GENERAL, I5 I8, Exp. I3, Imagen I0I-I03.

Archivo Histórico Nacional, Madrid.

Declaración de Ramón Sánchez Pegalajar (3I de julio de 1936).

FC-CAUSA_GENERAL, I5 I8, Exp. I3, Imagen 35-38.

Archivo Histórico Nacional, Madrid.

Declaración de Vicente López Coterilla Vazquez (8 de agosto de 1936). FC-CAUSA_GENERAL, I 5 I8, Exp. I3, Imagen 220-222. Archivo Histórico Nacional, Madrid.

Graham, H. (199I). Socialism and war: the Spanish Socialist Party in power and crisis, 1936-1939. Cambridge: Cambridge University Press.

Juliá, S. (1996). "Antecedentes políticos: la primavera de 1936”, en Malefakis, E., La guerra de España. 1936-1939 (pp. 49-76). Madrid: Taurus.

La Libertad (16 de Agosto de 1936). "Los responsables de la sedición militar de Madrid”. La Libertad, p. 3. 
Lozano, I. R. (9 de noviembre de 20 I0). Entrevista personal Bibliografía a Andrés Manzano. Madrid, España.

(5 de febrero de 20II). Entrevista personal a Cipriano y Andrés. Madrid, España.

Miranda, F. A. (20I I). Julio de 1936. Conspiración y alzamiento contra la Segunda República. Barcelona: Crítica.

Montero, S. (2009). La batalla de Brunete. Madrid: Raíces.

Ramírez, J. M. (2007). La batalla del Jarama. Febrero 1937. Madrid: Almena.

Rojo, V. (20I0). Historia de la Guerra Civil española. Barcelona: RBA.

Romero, L. (1976). Tres días de julio. Barcelona: Ariel. (1996). "Fracasos y triunfos del levantamiento", en Malefakis, E., La guerra de España. 1936-1939 (pp. 77-I08). Madrid: Taurus.

Venero, M. G. (1967). El general Fanjul: Madrid en el Alzamiento Nacional. Madrid: Cid. 